\title{
Moral Development and Citizenship Education in Vocational Schools
}

\author{
Hélène Leenders, Wiel Veugelers, and Ewoud de Kat \\ Department of Child Development and Education, University of Amsterdam, 1012 WX Amsterdam, The Netherlands \\ Correspondence should be addressed to Wiel Veugelers, w.m.m.h.veugelers@uva.nl
}

Received 27 February 2012; Accepted 13 May 2012

Academic Editor: Kirsi Tirri

Copyright (C) 2012 Hélène Leenders et al. This is an open access article distributed under the Creative Commons Attribution License, which permits unrestricted use, distribution, and reproduction in any medium, provided the original work is properly cited.

We investigate the objectives, practical application, and learning outcomes of moral education and citizenship education at three vocational schools in the Netherlands (VMBO). We explore teachers' and students' pedagogical, sociopolitical, and moral development objectives and how they deal with values, dialogue, and diversity. We continue with how the objectives get materialized in practice and teachers' and students' perceptions of the learning outcomes. The study shows that there is a strong agreement between teachers and students about the importance of objectives of moral education and citizenship education. Schools differ in how sharply they focus on social and political aspects, and in how reflective and dialogical their approaches are. The differences revealed in the moral education approaches can be largely linked with differences in their cultural environment.

\section{Introduction}

Citizenship development is an important theme in current political initiatives and public debate, and education has an important role to play. Governments in various countries have incorporated citizenship development into education in recent years $[1,2]$. The Dutch Minister of Education submitted a legislative proposal in 2006 that asks schools to actively promote citizenship and social integration. The minister defines social integration as the participation of citizens in society and its institutions, as well as social participation and familiarity with and knowledge of Dutch culture. The government gives schools the freedom to interpret citizenship education further in their own way.

There is a strong international debate on citizenship education in the political and academic worlds, and given the cultural and social challenges facing Dutch society, we think it is important to examine how moral education and citizenship are being implemented in Dutch secondary education. In a first study we had a survey among teachers of secondary education [3]. In the next two studies we went more into the practice of schools. This study focuses on vocational (VMBO) schools. This VMBO study follows a comparable study in preuniversity (VWO) schools [4]. $\mathrm{VMBO}$ schools are the lower tracks in vocational education; it is a four-year programme. The students involved are 15 years old.

Since schools have possibilities to interpret citizenship education, it is interesting to document examples of divergent practices in schools. We selected out of our survey study three schools with the greatest possible variety, in terms of location (rural, medium-sized town, and major city), school size (small, medium-sized, and large), and students' cultural background (mainly white, multiethnic, and minority ethnic schools).

The study in these three schools covered the research questions that goals teachers find important and what learning outcomes they observe. The reason that we focus on teachers is that they have the professional role of putting educational policy, the pedagogical concept of the school, and their own cultural-pedagogical aims into practice. Teachers make the curriculum and, consciously or not, they tend to influence their students' moral development. It is important for teachers to be aware of the moral values they wish to encourage, the type of citizenship they are aiming for, and what form of practical support they give students in 
their personal moral development. Students' opinions about citizenship education are also important. They are, after all, the targets of citizenship education. Many advocates of citizenship education see students as active participants, who develop their identity through reflection and action. We have accordingly included the student perspective in the study.

\section{Theoretical Framework}

2.1. Citizenship Education and Moral Development. The current debate on young people's social development is imbued with the concept of "citizenship." The focus in citizenship education can differ. Citizenship education may focus on transferring knowledge on democracy, its institutions, and the structure of society [5]. Equally, the approach could be more on promoting particular social norms, or on an active construction of moral signification [8]. We endorse the latter approach, in which the individual's social performance is linked with participation in society [6]. Moral values to be developed in such a perspective are "justice," "autonomy," and "social and moral commitment."

Citizenship is not restricted to the political domain but also relates to the civil society, to the everyday relations between people, and to individuals' identity development [7]. If citizenship education is to be more than merely an explanation of rights and duties, or a sort of behaviouristic conformity, then it has to be anchored in a firm foundation of moral development. There is a growing tendency to link moral development and citizenship development [8-10]. The relationship between citizenship education and moral development is that the value development guides the citizenship development, in particular the development of attitudes. A morally founded citizenship education may encourage young people to actually apply their knowledge and skills, and to act morally and socially. Citizenship education may by improving moral reasoning and action also become more reflective and dialogical and therefore susceptible to changing attitudes [11].

In the Dutch policy on citizenship education the view is that the educational objectives for active citizenship and social integration must address the cultural diversity in society. Cultural and ideological diversity with values such as "tolerance" and "respect for differences" should be dealt with in education $[12,13]$. Teachers can address these issues in various ways. They might, for instance, present the Netherlands as a multicultural society and attempt to start a dialogue in their lessons between different cultures and world views, or they can stress the Dutch historical canon with a focus on the Christian tradition. We pay attention to sociopolitical objectives in citizenship education because citizenship education is always embedded in political relations $[14,15]$. The formal Dutch policy focus on social cohesion and social integration in citizenship education is a particular intervention in this power relationship. A key element in the sociopolitical objectives we investigate is attitude formation, which acts on two levels: "social involvement" (involvement with others, solidarity with others) and "political engagement" (the development of an attitude that promotes equality and democracy in society).
2.2. Teachers and Values. Values are an integral part of teaching, reflected in what is taught and also in how teachers and students relate to each other. Teachers express values through their choice of subject, the examples they use, and in how they supervise their students [16]. Teachers can convey certain values, but they can also create conditions in which multiple perspectives are presented. Teachers are always, whether consciously or hidden, trying to influence students' moral development. Education simultaneously stimulates the development of certain values and the skills to enable students to form their own opinions.

Curriculum researchers point out that attention is needed in research for the underlying pedagogical objectives that control the actual teacher actions [17]. Research into teachers' pedagogical actions refers consistently to the importance of objectives, particularly in value-laden contexts [18]. In earlier studies $[19,20]$, we presented teachers, students, and parents with pedagogical objectives based on the work of Oser [21], Berkowitz [22], and others. These studies produced a reliable and valid instrument for measuring the attention given to pedagogical objectives. The instrument itself covers "social development," "autonomy," and "disciplining."

Teachers can use different pedagogical-didactic methods in moral and citizenship education $[8,23]$. We differentiate in this study between one oriented to practical social conduct ("social conduct"), one which revolves around actual, predefined values, ("value transfer"), and one in which values are the subject of reflection and communication ("value communication") [20, 24]. Moral dialogues in school are seen as a crucial aspect of moral education $[9,25,26]$. When examining how values are communicated in the citizenship education class, we distinguish between the opinion-forming process ("discussion") and the more "sociopolitical content of opinion forming."

In summary, in this study we are interested in the pedagogical objectives in citizenship education in particular in the sociopolitical domain, the moral development objectives that are interwoven with citizenship education, and how these objectives take shape in educational practice with particular attention to dialogues and diversity.

\section{Research Questions}

We formulated the following research questions based on the theoretical framework.

(1) Which pedagogical and sociopolitical objectives find teachers and students important, and which learning outcomes do they observe?

(2) Which are the learning outcomes in moral development observed by teachers and students?

(3) Which forms of practical application of moral education are considered desirable by teachers and students, with regard to:

(a) the pedagogical-didactic approach,

(b) moral dialogues,

(c) cultural and ideological diversity. 
Teachers shape moral education in a school in practice, and it is the students who experience moral education every day. In this study we used questionnaires to investigate teachers' and students' objectives, moral education practice, and assessment of learning outcomes. The survey was accompanied by observing lessons and interviewing teachers and students. The interviews involved the same moral education aspects as in the questionnaire, presented as open questions. We occasionally used data from the interviews and observations when interpreting the findings. The research questions explore what teachers think, what students think, and differences between the schools.

\section{Survey Instrumentation and Execution}

4.1. Teachers' and Students' Questionnaires. The questionnaires were oriented to teachers' and students' goals, the practical application of moral education, and the reported learning outcomes. The content of the teachers' questionnaire and students' questionnaire were related. For example, if the teachers were asked to state the objectives they consider important and the extent to which they achieve them, the students were asked which objectives they consider important and how well they think they are achieved at school.

The questionnaire used in the survey was based on measurement instruments used in earlier studies and is similar to the study in preuniversity schools [3]. The questionnaire has six parts: "Pedagogical objectives," "Sociopolitical domain in the curriculum," "Moral development," "Pedagogical-didactic approach," "Moral dialogues in school," "Cultural and ideological diversity." Each part of the questionnaire involves one or more scales. The internal consistency of the scales used is good (Cronbach's alpha is between 0.75 and 0.93 ).

4.1.1. Pedagogical Objectives. The pedagogical objectives comprise three scales: "disciplining" ( 4 items, $\alpha=.83$ ), "autonomy" ( 4 items, $\alpha=.81$ ), and "social development" (7 items, $\alpha=.89)$. These scales were derived from an earlier survey [3]. The respondents were requested to rate the objectives they would like to achieve, and the extent to which they consider they have been achieved, on a 5-point scale.

4.1.2. Sociopolitical Domain in the Curriculum. Teachers' objectives in the social domain were measured with the "concern for others" scale from the Child Development Project [25]. This scale measures teachers' attention to "social involvement" (7 items, $\alpha=.89$ ): solidarity with others and concern for and involvement with others. We developed a second, more politically oriented scale. Our "political engagement" scale ( 4 items, $\alpha=.75$ ) measures teachers' attention to the development of an attitude oriented to creating equal opportunities for all, and a critical attitude towards inequalities in society. We also investigated how teachers consider these objectives have been achieved (learning outcomes).

4.1.3. Moral Development. We asked teachers what they thought students had learned in moral development, for which we used the "Dimensions of Moral Personality Questionnaire" $[20,27]$. The scales concerned were "exchange of points of view" (6 items, $\alpha=.88$ ), "insight into sociomoral situations" (5 items, $\alpha=.89$ ), and "sociomoral attitude" (5 items, $\alpha=.87)$.

4.1.4. Pedagogical-Didactic Approach. We examined teachers' pedagogical-didactic actions on three scales: (1) "value transfer" ( 5 items, $\alpha=.76$ ), with items such as "I convey defined values and standards to the students"; (2) "social conduct" ( 6 items, $\alpha=.81$ ), with items such as "I ensure that students behave in a social way"; (3) "value communication" (6 items, $\alpha=.89$ ), with questions such as "I am happy for students to have different views on matters." For "social conduct" we use the "Promotion of social understanding and prosocial values" scale from the Child Development Project [25]. The other two scales we developed ourselves and have used them in an earlier survey [19].

4.1.5. Moral Dialogues in School. We investigated how communication on values took place in the class and what people wanted based on the two scales, "discussion" (7 items, $\alpha=.91$ ) and "socio-political opinion forming" (5 items, $\alpha=.84$ ). The questions were derived from the "Elicitation of student thinking and active discussion" scale from the Child Development Project [25] and the "Attitudes to open classroom climate" scale from the IEA Citizenship Education Study [1]. The CDP scale is oriented to the opinion-forming process, with items such as "I respond with more questions to students' answers" and "I establish connections between students' different points of view." The IEA scale is oriented to the sociopolitical content, with items such as: "I encourage students to form their own opinion on political and social issues."

4.1.6. Cultural and Ideological Diversity. In order to determine how much attention teachers wish to give to cultural and ideological diversity, and how much they actually do, we present them with statements such as "I give the students in my lessons an opportunity to speak about their own culture or religion” [20] (7 items, $\alpha=.93$ ).

4.1.7. Characteristics Teachers and Students. We asked teachers their age, gender, and what subject they teach. We asked students their age, gender, personal religious beliefs, country of origin and school grade, and their chosen subjects. We wish to investigate whether the students of the three schools differ in these characteristics, and whether there might be a relationship between the student characteristics and their opinion on moral education.

4.2. Participating Schools, Teachers and Students. We selected the schools with a perspective to obtain the greatest possible variety, in terms of location (rural, medium-sized town, and major city), school size (small, medium-sized, and large), and students' cultural background (mainly white, multiethnic, and minority ethnic schools).

4.2.1. Rural School. School 1 is a small Roman Catholic rural school in the south of the Netherlands. The school site 
that was involved in the study accommodates only thirdyear and fourth-year students, with some 250 students. About half of them, 128 students follow the office work vocational programme and participate in the research. The student questionnaire was administered by the mentors in all six classes, yielding 120 completed questionnaires. Of the participating students, $86 \%$ were of Dutch origin, and $14 \%$ of foreign origin (7\% Turkish or Moroccan; 2\% Surinamese/Antillean; and 5\% from other countries, mainly West or Central African countries). The teacher questionnaires were issued to teachers whose students are in the third and fourth years of the vocational programme, which amounts to 58 teachers at this school. Of these, 28 teachers returned completed questionnaires, which is a response of $48 \%$.

4.2.2. Town School. School 2 is a medium-sized Protestant Christian town school, also in the south of the country. It has 524 students at the school site where the study was conducted. Of these, 112 students are in the third and fourth years of the office work vocational programme. Mentors in the five classes administered the student questionnaires, 96 of which were completed. Of the participating students, $46 \%$ are of Dutch origin, and 54\% of foreign origin (38\% Turkish or Moroccan; 4\% Surinamese or Antillean; and 12\% from other countries). Of the 47 teachers of these students, 20 completed the questionnaire (response: $43 \%$ ).

4.2.3. Major City School. School 3 is a nondenominational school for vocational education in Amsterdam (major city school). This is a very large school with 850 students at the study site. There are only 55 office work vocational students. There were therefore far fewer survey participants, both students and teachers, at this school. 48 of the 55 students filled in the questionnaire. These students, $6 \%$ were of Dutch origin, and 94\% of foreign origin (59\% Turkish or Moroccan, 10\% Surinamese/Antillean; and 25\% from West or Central African countries). Only 36 teachers work with this school's office business vocational and theoretical programmes. Questionnaires were issued to all these teachers, and 12 completed and returned them (response: 33\%).

The teachers' responses of each school came from teachers of diverse subjects. The ratios of older and younger teachers, men and women, and their cultural backgrounds, were largely consistent with the actual ratios in the schools. There is no reason to doubt the representativeness of the respondents for the schools concerned.

4.3. Data Analysis. The differences between the schools were investigated with a one-way analysis of variance. Table 1 shows the teachers' average scores for the three schools for the objectives. Table 2 shows the corresponding scores for practical application.

\section{Results}

The first section discusses the teachers and the differences regarding teachers between the schools; the next section continues with the students of the various schools; finally the third section comments on the differences between teachers and students.

\subsection{Teachers}

5.1.1. Pedagogical Objectives and Social-Political Domain in the Curriculum. The teachers at all schools state that they consider the pedagogical objectives "disciplining," "social development," and "autonomy" to be "important" (M 4.30, $4.47,4.23)$. Teachers consider the more sociosocietal objectives ("social involvement" and "political engagement") to be less important, in particular "political engagement" (M 3.70, 3.39). The learning outcomes show according to the teachers a similar pattern. "Autonomy" and "social involvement" are not that easy to realise (M 3.30, 3.04). "Political engagement" is even difficult to realise (M 2.48).

We found no significant differences between teachers of the three schools in terms of pedagogical objectives. In terms of promoting "social involvement" and "political engagement" they differ. The teachers at the rural school want to focus less than teachers of the town school and the major city school on "political engagement" and they state that they achieve less "social involvement," among their students than teachers in the major city school. In the sociosocietal domain the rural school lags behind the two urban schools.

5.1.2. Moral Development. We inquired only the effects that are being mentioned, not the intended goals. The teachers report that their students acquire the more cognitive skill "exchange points of view," the more cognitive insight "socialmoral insight," and the attitude "social-moral attitude" in equal measure (M 3.11, 3.13, 3.09). The teachers at the major city school estimate the learning outcomes for both dealing with "exchange points of view" and "social-moral" insight significant higher than their counterparts in the other two schools.

5.1.3. Pedagogical-Didactic Approach. The pedagogical-didactic approach to moral education can be oriented to "value communication," "social conduct," and "value transfer." All three approaches are important in moral education, as teachers invariably agree (M 3.91, 4.24, 4.30). Teachers score "value transfer" and promoting "social conduct" slightly higher than the more reflective "value communication." We observe this tendency both in the desired and the practical application (M 3.40, 3.82, 4.02). In practice teachers are a lot involved with the more ideological transfer of values, less with the more behaviour modification of social conduct, and much lesser with the more reflective and dialogical value communication. For these methods we find no significant differences between the three schools.

5.1.4. Moral Dialogues in School and Cultural and Ideological Diversity. We focused more on the didactics, in particular the more socio-political element. "Discussion" is more desired than "sociopolitical opinion forming" (M 4.09, 3.76), and the practice shows the same pattern ( $M$ 3.65, 3.47). Paying attention to "cultural and ideological diversity" is not 


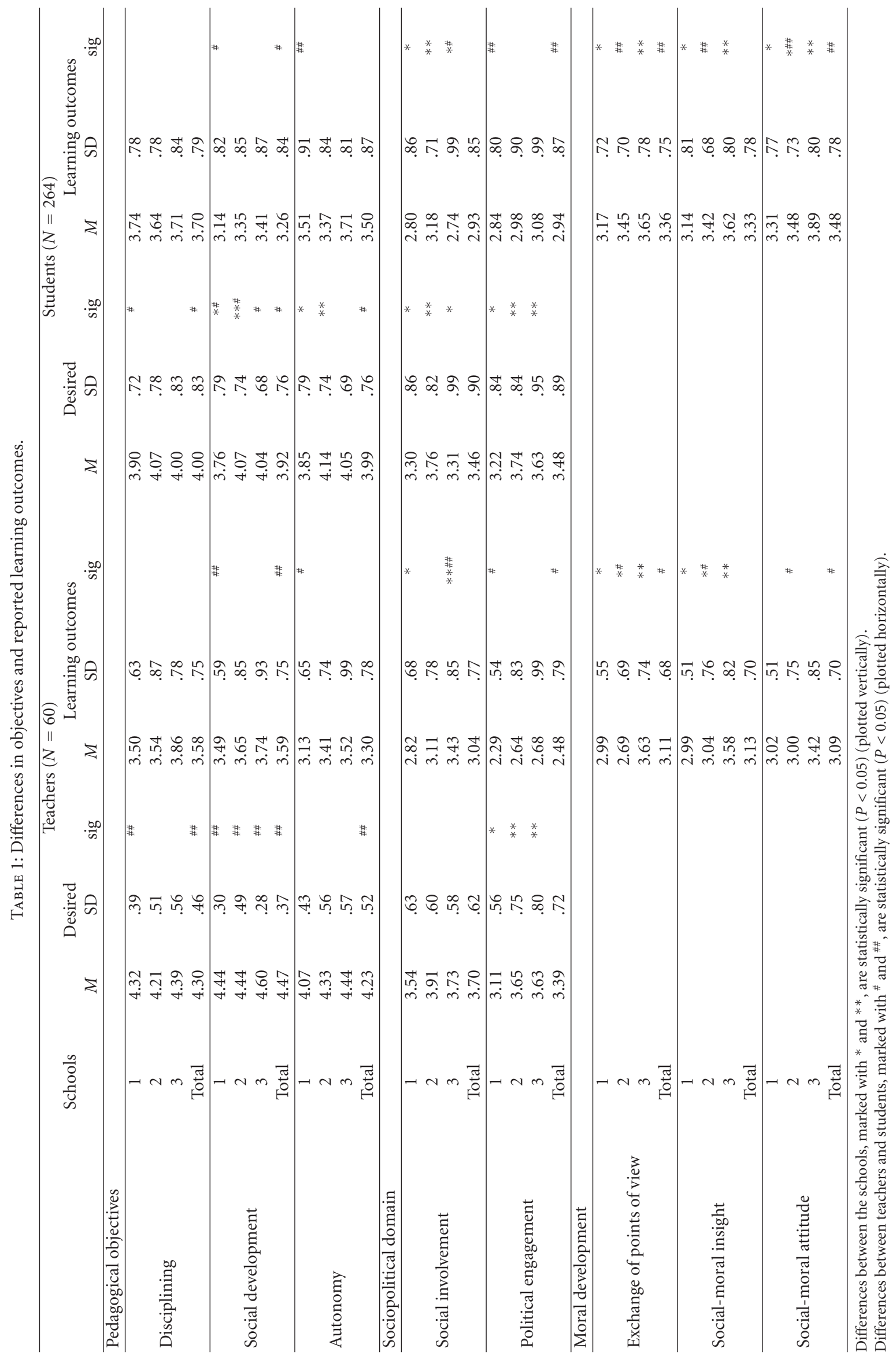




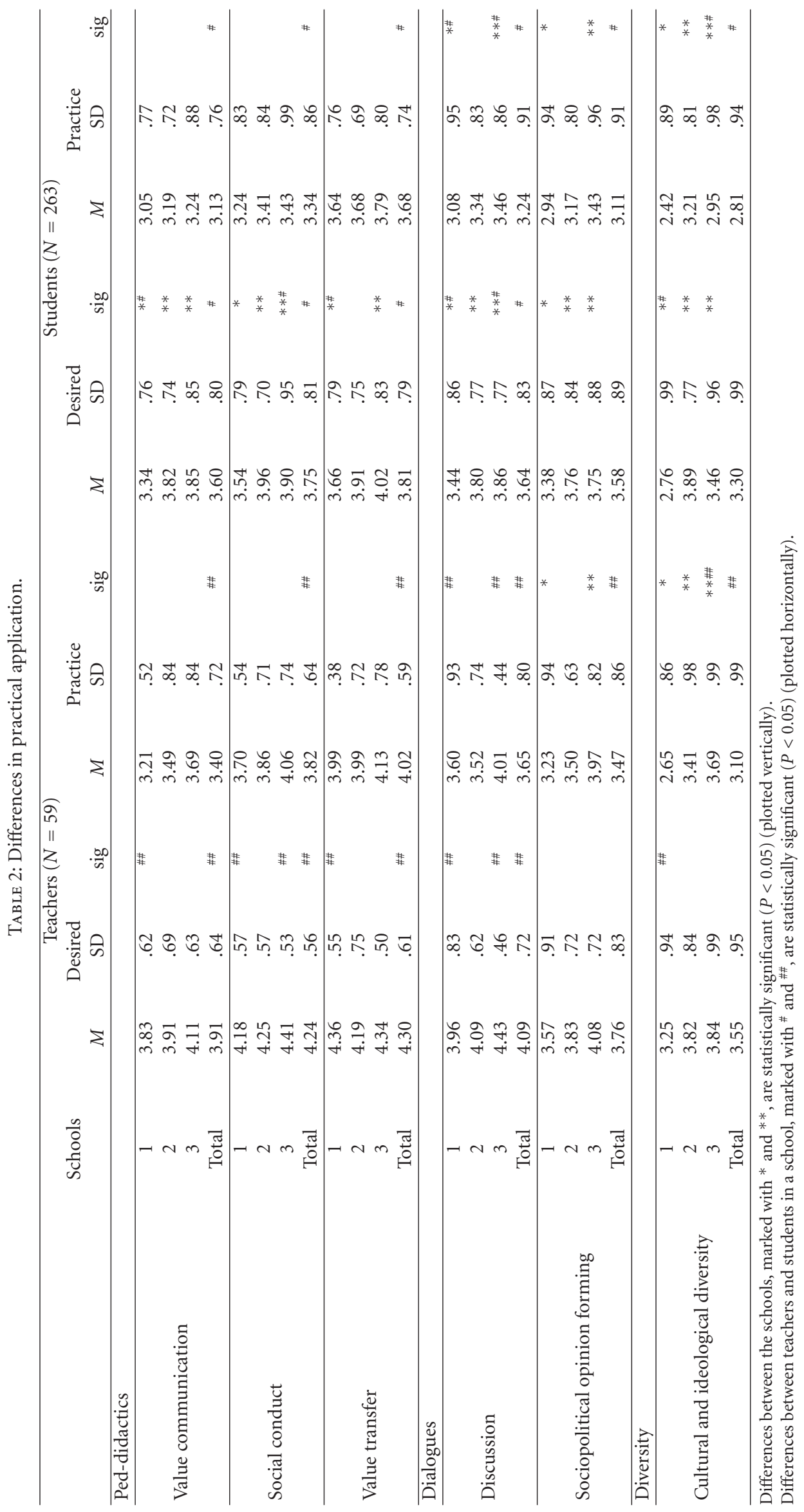


considered as very important and not much practised (M $3.55,3.10)$.

There are differences between the schools. The rural school's relatively low scores are conspicuous. The teachers concerned say that they give less attention to "political opinion forming" than their counterparts in the major city schools. The teachers at the "mainly white" rural school report giving the least attention of all to cultural and ideological diversity, namely only "a little." This is in sharp contrast with the multicultural town school and in particular the ethnic minorities school in the major city, where the teachers appear to succeed well in giving substance to this element of moral education.

Interesting to see is that in the major city school there is only a small difference between the desired attention and the attention in practice for "political opinion forming" and "cultural and ideological diversity."

5.2. Students. What do students think about objectives, outcomes, and pedagogical-didactic methods?

5.2.1. Pedagogical Objectives and Social-Political Domain in the Curriculum. Students consider all pedagogical objectives "disciplining," "social development," and "autonomy" to be important (M 4.00, 3.92, 3.99). Students consider the sociopolitical objectives "social involvement" and "political engagement" less important (M 3.46, 3.48). There are several differences between the schools. The town school students attach great importance to the objectives social development and autonomy - unlike the rural school students. Regarding sociosocietal aspects, these town school students attach more importance than all other students to acquiring "social involvement." The students at the town school consider the importance of "political engagement" to be almost on a par with "social involvement." The situation is reversed at the major city school, where the students consider "political engagement" to be important "social involvement" somewhat less.

The learning outcomes show the same pattern as the desired objectives. The sociopolitical objectives (M 2.93, 2.94) are less realised than the pedagogical objectives (M $3.70,3.26,3.50$ ). Students think that in particular they learn "disciplining" and also "autonomy." The rural school students lag behind in social and sociopolitical objectives ("social development," "social involvement," and "political engagement"), so are the learning outcomes they report.

5.2.2. Moral Development. Students think that they learn quite a lot of the three aspects of moral development: "exchange points of view," "social-moral insight," and "socialmoral attitude" (M 3.36, 3.33, 3.48). Students at the three schools differ greatly in their opinions about moral development learning outcomes. Of all schools, the major city school students produce the highest estimates of learning outcomes for all moral development aspects; the rural school is the lowest on this point for all aspects. Surprisingly, vocational school students are the most optimistic about what is generally viewed as the hardest aspect of moral development: translating insights into attitudes. Maybe these students find the more cognitive aspects relatively difficult, but attitude development comparatively easy.

5.2.3. Pedagogical-Didactic Approach. Students have no outspoken preference for one particular pedagogical-didactic approach; like the teachers, they opt for a combination of "value communication," "social conduct," and "value transfer" (M 3.60, 3.75, 3.81). The rural school students score consistently lower than the others on the amount of attention they think should be given in practice to the various approaches. According to the student's teachers do a lot on value transfer and less on value communication (M 3.13, $3.34,3.68)$.

\subsubsection{Moral Dialogues in School and Cultural and Ideological} Diversity. Students desire "discussion" and "sociopolitical opinion forming," and to a lesser extend attention for "cultural and ideological diversity" (M 3.64, 3.58, 3.30). The rural school students also have the lowest scores of all students: they have the least desire of all to learn to conduct dialogue or to learn to put forward substantive arguments for political opinion forming. The attention they wish to give to cultural and ideological diversity is likewise the lowest of all students. The town school and major city school students want considerable attention to be given to teaching skills for conducting dialogue and for political opinion forming.

Students of the rural school assess their school as the one in which the least attention is given to all these moral education aspects in practice. For example, they consider that their school pays only "a little" attention to the cultural and ideological diversity theme. The major city school students give scores for actual practice that are higher than those for the other two schools. Students of the town and major city students assess the amount of attention given to these themes in practice as higher than the assessment in the rural school. These scores are relatively high for such a difficult theme.

5.3. Differences between Teachers and Students. We examine the differences between teachers' and students' scores in order to ascertain:

(i) whether what teachers want in terms of objectives and practice corresponds with what students want;

(ii) whether students confirm teachers' assessment of what proceeds in practice;

(iii) whether students actually perceive the learning outcomes that teachers claim to achieve.

The statistically significant $(P<0.05)$ differences between teachers and students are shown in Tables 1 and 2. The differences can be seen on the horizontal axis, as distinguished by the \# and \#\# marks.

\subsubsection{Pedagogical Objectives and Social-Political Domain in} the Curriculum. The data show that students assess all pedagogical objectives ("disciplining," "social development" and "autonomy") and "social involvement" as less important than their teachers do, whereas the students attach even more importance than the teachers to the "political engagement" 
objectives. In all the three schools students find "political engagement" more important than the teachers. In all the schools there is a strong discrepancy between teachers and students on the social development objectives. Teachers find them far more important than students. The differences between teachers' and students' assessments of the importance of "disciplining" are most pronounced at the rural school.

5.3.2. Learning Outcomes. The assessment of learning outcomes shows interesting patterns. Students estimate the learning outcomes higher than the teachers for "disciplining," "autonomy," and in particular "political engagement." Teachers score higher than students for the "social development" and "social involvement."

The rural school students differ from their teachers in their estimates both of how much "autonomy" and of how much "political engagement" they learn at school. The rural school students state that they learn less social development than their teachers claim, and the major city school students perceive that they learn less social involvement than their teachers think. There are no significant differences between students and teachers in the town school.

\subsubsection{Discrepancy between Desired Objectives and Learning} Outcomes. If we examine the differences between the scores for the desired pedagogical and sociosocietal objectives and the learning outcomes of these objectives, the teachers exhibit a greater discrepancy than the students between what they want and what they think is being learned (the discrepancies in the teacher scores are between .70 and 1.00; and in the student scores up to .75). There is one interesting exception to this pattern. The major city school teachers are reasonably satisfied with the amount of "social involvement" acquired by their students (difference only .30), whereas the students perceive a greater difference between what they want to learn in this area and what they observe (difference is .60). The major city school students apparently think that they do not learn enough "social involvement" at school.

5.3.4. Moral Development. The students are generally more optimistic than the teachers in their assessment of moral development at the end of their school careers. Students state that when they finish school they will be able to deal with diverse opinions "moderately well," that they have "moderate" insight into the interrelationship between their own experiences, attitudes, and opportunities compared with those of other people ("socio-moral insight"), and know how to behave accordingly ("socio-moral attitude"). The greatest difference in assessment between students and teachers is evident at the town school, where there are statistically significant differences between the teacher scores and the student scores for all moral development clusters.

5.3.5. Pedagogical-Didactic Approach. There is no clearsingle-dominant approach in vocational schools. The teachers and students in all three schools want a combined approach, which they also apply or receive in practice. Attention in practice for "value communication" lags somewhat behind "value transfer" and focuses on "social conduct." Both teachers and students may have difficulty with reflecting on values, clarifying personal values, and entering into dialogue with each other. Students in general want the various pedagogical-didactic approaches to be applied less than teachers would like, and they also think that less attention is given in practice to value communication and value transfer than teachers believe. We observe these differences in assessment most clearly in the rural school.

\subsubsection{Moral Dialogues in School and Cultural and Ideological} Diversity. If we look at a more specific interpretation of moral education in practice, at the opinions about moral dialogues in school, it is striking that the pattern is the same as described above: students want less attention to this aspect than teachers (this difference is significant at two of the three schools). Even more interesting is the observation that both parties actually agree completely about the desirability of "political opinion forming."

In terms of the attention given to cultural and ideological diversity, it would appear that each school presents a different picture. The rural school students want less attention to this point than the teachers, whereas both parties agree that the realized attention is low; it is conspicuous that teachers and students at the town school are close to agreement on how much attention is needed and how much attention is actually given to this theme; whereas a salient point at the major city school is the students' considerably lower assessment of attention in practice compared with the teachers. It is striking that the diversity theme at the "mainly white" rural school is hardly an issue either for teachers or students, while they agree on its importance at the multiethnic town school.

\section{Conclusions and Discussion}

The schools involved in this study differed considerably: a mainly white rural school, a multiethnic, medium-sized school in a medium-sized town, and a large, ethnic minorities school in a major city.

If we turn our attention to the teachers, it would appear that the rural school lags conspicuously behind in the broad, social area compared with the other vocational schools. This is true in terms of both objectives (deeming "political engagement" least important of all schools); and pedagogical-didactic approach (little attention to "political opinion forming" and "cultural and ideological diversity"). The school likewise scores lower than the others in the social area. This school conveys the least "social involvement," and the low scores for "exchange of points of view" and "socio-moral insight" point moreover to a lack of learning in the area of moral reflection.

The teachers at the multiethnic town school did have a clear social interest: "political engagement" was deemed important and considerable learning outcomes were reported in "cultural and ideological diversity." This school differs markedly from the mainly white rural school in this respect. If we compare this school with the ethnic minorities school in the major city, the two schools do not differ in 
their abstract pedagogical objectives and pedagogical-didactic approach, but have dissimilar reflective objectives.

The teachers in the major city school report the greatest learning outcomes for the cognitive aspects of moral development ("exchange of points of view" and "socio-moral insight") and for "socio-political opinion forming." This means that the teachers in the major city perceive that lessons are learned for being able to exchange points of view and having respect for different opinions, and having insight into sociomoral situations. They also perceive that their students learn to give more attention to the sociopolitical content in moral dialogue and to make up their own minds about political and social issues.

As perceived by the students, there is a difference between the mainly white rural school on the one hand, and the multiethnic town school and the minority ethnic major city school on the other. The students view their mainly white rural school as the least social, the least reflective, and the least socially oriented in terms of methodological and learning outcomes. This is consistent with what they themselves want: these students themselves have the lowest aspirations of all students in these three areas. They have the lowest scores on objectives for "social development" and "autonomy," as well as for "social involvement" and "political engagement." They also have the lowest aspiration of all students for attention to discussion (learning to enter into dialogue) and "cultural and ideological diversity."

The students at the multiethnic town school have the clearest desire for a combination of social, reflective, and social aspects. They have the highest aspirations for both "social development" and "forming critical opinions," as well as for "social involvement" and "political engagement." Although the students at the minority ethnic school in the major city report the highest learning outcomes for moral development, the students of this school report that they learn the least "social involvement" of all students.

In summary, we may draw the following conclusions.

(i) There is a reasonable consensus among teachers and students that moral education at the mainly white rural school is neither reflective nor socially or society oriented. The students are therefore inadequately prepared for the multicultural society.

(ii) Teachers and students of the medium-sized town school with the multiethnic student population consider that moral education impinges upon all three of the areas: social, reflective and societal (with the reflective, and moral development somewhat under pressure).

(iii) Teachers and students of the ethnic minorities school in the major city combine social attention with a reflective attitude; but the social aspect is at risk of falling behind. Students are prepared for the multicultural society, but compared with the attention given to the political and cultural aspects, too little is given to the social aspect.

We are cautious in explaining the differences between the schools. The three main differences are: cultural diversity of the school, denomination (Roman Catholic, Protestant, Nondenominational/Public), community (rural, town, and major city). The community is strongly linked to the cultural diversity of the schools in the research. The denomination seems less directly linked to the outcomes. For example, in the Protestant school are many students from a Turkish or Moroccan origin.

6.1. Student Population and Cultural Diversity. It emerged from our earlier study of three mainly white preuniversity schools that they paid not a lot of attention to "socio-political opinion forming" and dealing with "cultural and ideological diversity" [4]. However, the students at these schools were in favour of attention being given to just these aspects. Their interest is more social and more society and politically engaged than their teachers tend to think.

This study of vocational schools shows that when there is a substantial or dominant proportion of students of foreign origin, more attention is given to "cultural and ideological diversity" and learning to deal with differences. The more multiethnic schools are, the more teachers and students tend to be aware of the importance of these aspects. As student interviews confirm, the diversity already exists within the school, and the students encounter the dialogue in and outside the school. The students at the minority ethnic school in the major city were the most familiar with the diversity theme. They were unanimous that "the more nationalities at a school, the fewer problems there are": they simply rub along together, as a matter of routine. However, they do point out that their teachers tend to be reluctant to raise strongly value-laden themes. Some of the students consider this actually to be outside the teachers' duties, while others disapprove of them sidestepping these issues. All students agree that they learn to get on with each other in a broad sense in particular on the playground-not so much in the classroom. From the point of citizenship education you can question if attention for cultural diversity is strongly linked to the presence of ethnic minorities. Should not it be a normal objective for all schools, regardless of the diversity of its students?

6.2. Moral Development and Political Development. Although the high students' "socio-moral attitude" scores would appear to be reason for optimism, in that attitude forming is a vital part of moral development, a focus on the moral and cognitive foundation of attitudes should nonetheless not be overlooked. It continues to be important to focus on the more reflective "social insight" and "exchange of points of view" if social behaviour is to be grounded in personal moral identity, and not merely adapted to the situation at hand.

The observed versatility in the pedagogical-didactic methods is favourable (with attention to transferring values, value communication, and good conduct), but teachers and students find value communication awkward. Learning to reflect on values, clarifying personal values, and entering into dialogue about values deserve additional attention in vocational education, also with embedding moral attitude forming, as mentioned above.

A very interesting point is the reluctance of teachers in the sociopolitical domain, in particular for "political 
engagement." Teachers seem to be anxious to be too political and prefer to focus more on the abstract pedagogical objectives "disciplining," "autonomy," "social development" and less on "social involvement" and "political engagement." Students themselves point to the desirability of political opinion forming; in particular the students of the major city school want to include the sociopolitical domain more. These results really ask for more theoretical and empirical research on the relationship between the moral and the political in citizenship education.

\section{References}

[1] J. Torney-Purta and J. Barber, "Democratic school participation and civic attitudes among European adolescents," Analysis of data from the IEA civic education study, Strasbourg, France, Raad van Europa, 2004.

[2] W. Veugelers, "Theory and practice of citizenship education. The case of policy, science and education in the Netherlands," Revista de Educacion, pp. 209-224, 2011.

[3] H. Leenders, W. Veugelers, and E. De Kat, “Teachers' views on citizenship education in secondary education in the Netherlands," Cambridge Journal of Education, vol. 38, no. 2, pp. 155170, 2008.

[4] H. Leenders, W. Veugelers, and E. Kat, in Getting Involved. Citizenship Education andSources of Moral Values, F. K. Oser and W. Veugelers, Eds., pp. 57-74, SensePublishers, Rotterdam, The Netherlands, 2008.

[5] E. Cleaver, E. Ireland, D. Kerr, and J. Lopes, "Citizenship education longitudinal study: second cross-sectional survey 2004," Listening to young people: citizenship education in England (DfES Research Report 626), London, UK, DfES, 2005.

[6] W. Veugelers and P. Vedder, "Values in teaching," Teachers and Teaching, vol. 9, no. 4, pp. 377-389, 2003.

[7] J. A. Banks, Diversity and Citizenship Education, Global Perspectives, Jossey-Bass, San Francisco, Calif, USA, 2004.

[8] H. Haste, "Constructing the citizen," Political Psychology, vol. 25, no. 3, pp. 413-440, 2004.

[9] W. Veugelers, "Creating critical-democratic citizenship education: empowering humanity and democracy in Dutch education," Compare, vol. 37, no. 1, pp. 105-119, 2007.

[10] W. Veugelers, "Youngsters in transformative and reproductive processes of moral and citizenship education," in Educating Moral Sensibilities in Urban Schools, K. Tirri, Ed., pp. 79-91, Senspublishers, Rotterdam, The Netherlands, 2008.

[11] W. Veugelers, Ed., Education and Humanism. Linking Autonomy and Humanity, Sensepublishers, Rotterdam, The Netherlands, 2011.

[12] L. Blum, "Race, community and moral education: kohlberg and Spielberg as civic educators," Journal of Moral Education, vol. 28, no. 2, pp. 125-134, 1999.

[13] W. C. Parker, “'Advanced' ideas about democracy: toward a pluralist conception of citizen education," Teachers College Record, vol. 98, no. 1, pp. 104-125, 1996.

[14] C. Mouffe, On the Political, Routledge, London, UK, 2005.

[15] W. Veugelers, "The moral and the political in global citizenship education," Globalisation, Societies and Education, vol. 9, no. 3-4, pp. 473-485, 2011.

[16] S. Gudmundsdottir, "Values in pedagogical content knowledge," Journal of Teacher Education, vol. 41, no. 3, pp. 44-45, 1990.

[17] I. F. Goodson, "Change processes and historical periods: an international perspective," in De Strijd om het Curriculum (the
Struggle about the Curriculum), W. Veugelers and R. Bosman, Eds., pp. 19-29, Antwerpen/Apeldoorn, Garant, 2005.

[18] D. T. Hansen, Exploring the Moral Heart of Teaching, Teachers College Press, New York, NY, USA, 2001.

[19] W. Veugelers and E. D. Kat, "Moral task of the teacher according to students, parents and teachers," Educational Research and Evaluation, vol. 9, no. 1, pp. 75-91, 2003.

[20] W. Veugelers and E. D. Kat, "Identiteitsontwikkeling in het openbaar onderwijs," (Identity development in public education), Antwerpen, Belgium, Garant, 2005.

[21] F. K. Oser, "Moral perspectives on teaching," in Review of Rsearch in Education, vol. 20, pp. 57-127, 1994.

[22] M. W. Berkowitz, Integrating Structure and Content in Moral Education, AERA, Chicago, Ill, USA, 1997.

[23] F. K. Oser and W. Veugelers, Eds., Getting Involved, Sensepublishers, Rotterdam, The Netherlands, 2008.

[24] W. Veugelers, "Different ways of teaching values," Educational Review, vol. 52, no. 1, pp. 37-46, 2000.

[25] M. Watson, V. Battistich, and D. Solomon, "Enhancing students' social and ethical development in schools: an intervention program and its effects," International Journal of Educational Research, vol. 27, no. 7, pp. 571-586, 1997.

[26] J. Schuitema, Teaching Values, Instituut voor de Lerarenopleiding, Amsterdam, The Netherlands, 2008.

[27] M. R. Buxairras, M. Martinez, E. Noguera, and A. Tey, "Teachers evaluate the moral development of their students," in Teaching in Moral and Democratic Education, W. Veugelers and F. K. Oser, Eds., pp. 173-192, Peter Lang, Berne, Switzerland, 2003. 


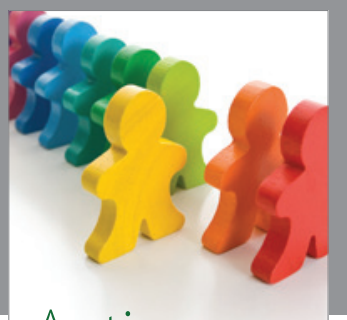

Autism

Research and Treatment
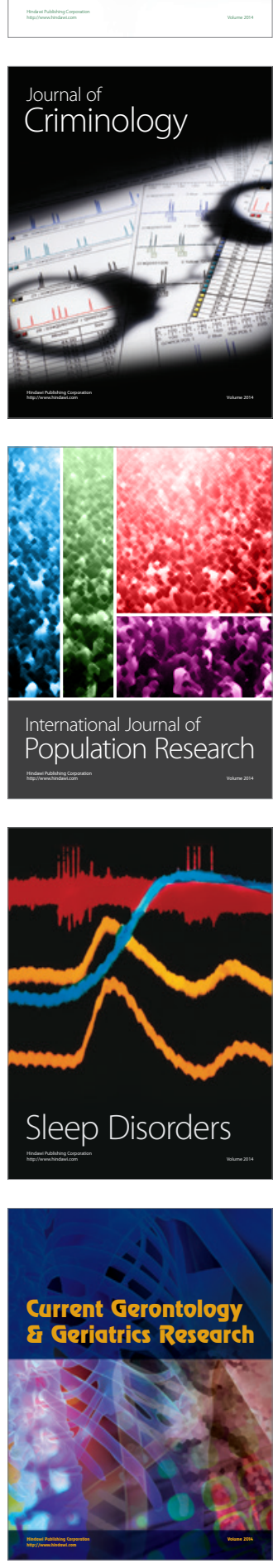
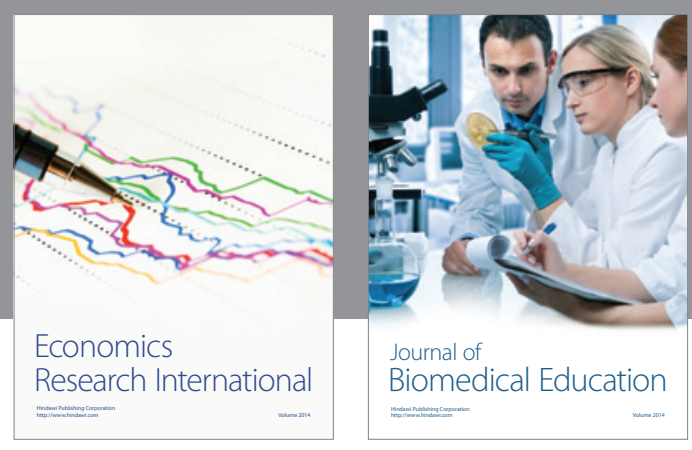

Journal of

Biomedical Education

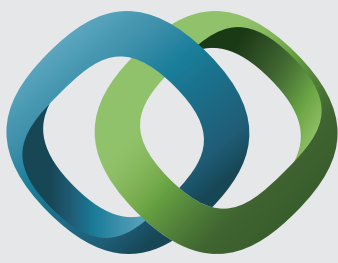

\section{Hindawi}

Submit your manuscripts at

http://www.hindawi.com
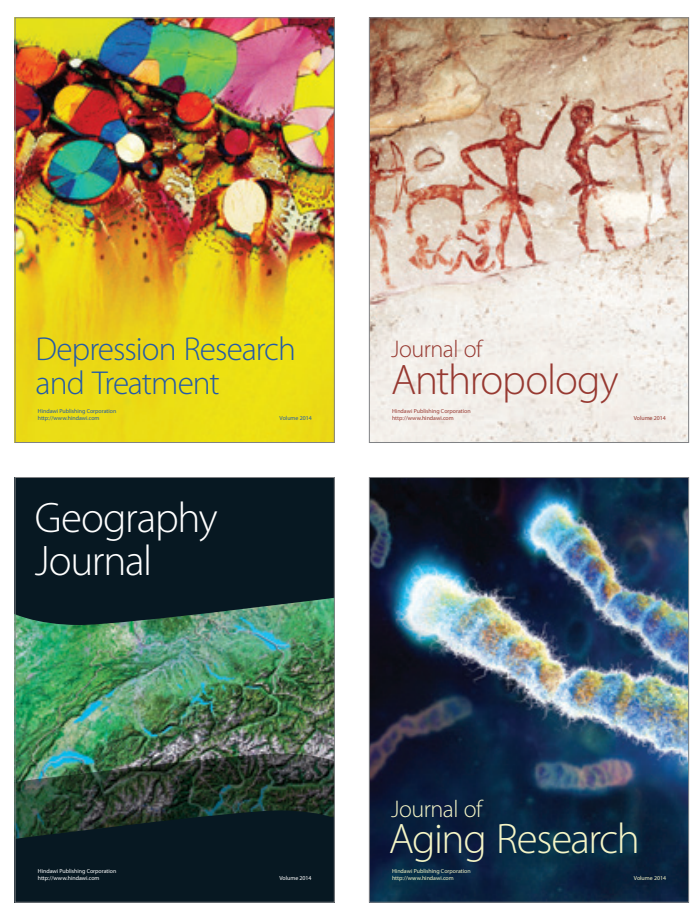

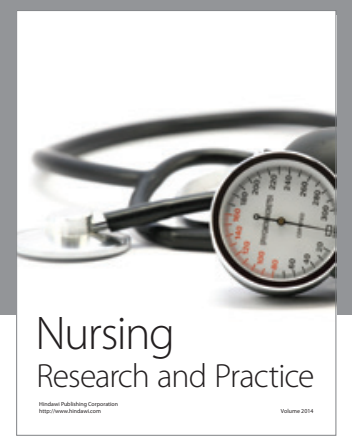

Nursing

Research and Practice

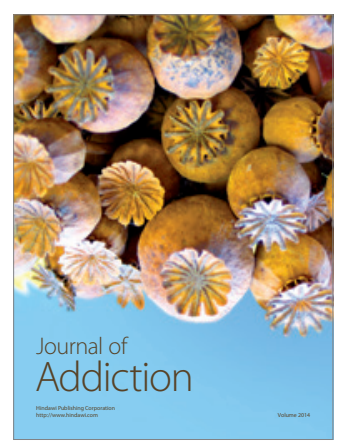

Child Development

Research

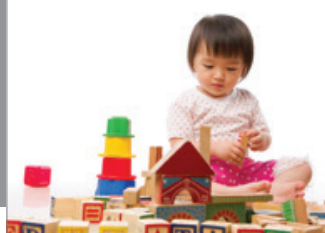

迥
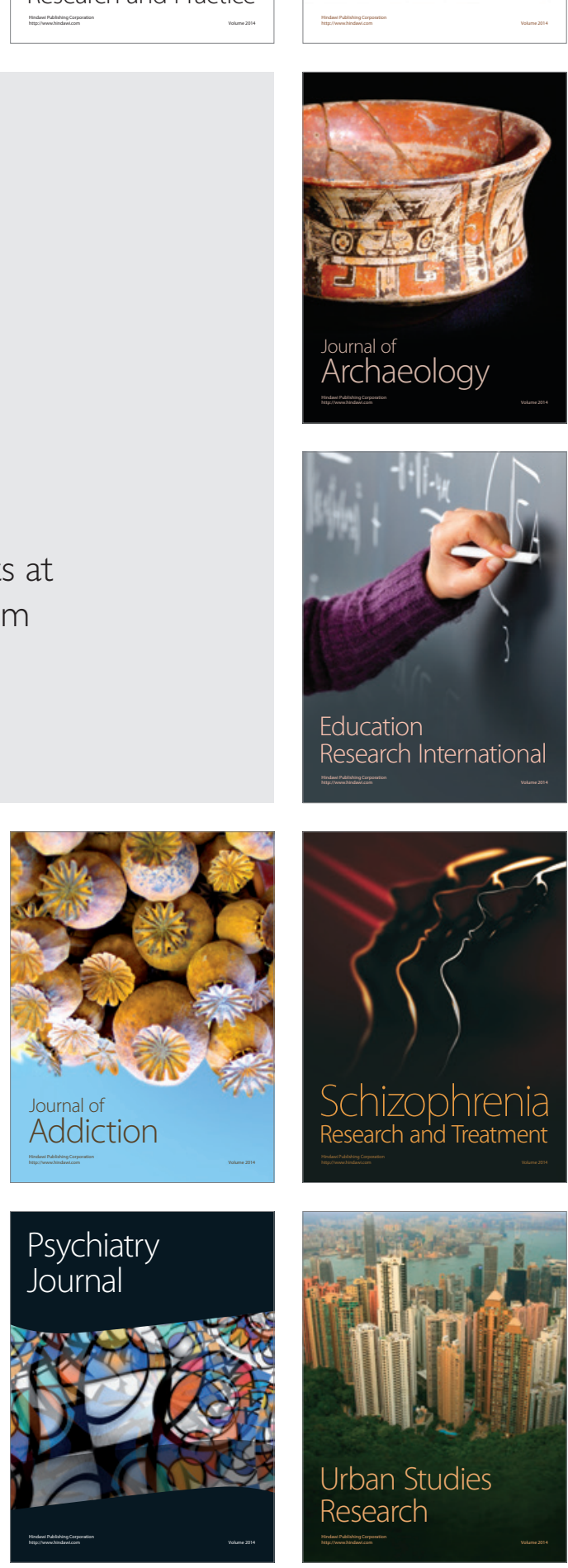